\title{
Investigating the Lubricity and Electrical Insulation Caused by Sanding in Dry Wheel-Rail Contacts
}

\author{
O. Arias-Cuevas $\cdot \mathrm{Z}$. Li $\cdot$ R. Lewis
}

Received: 29 August 2009/Accepted: 7 December 2009/Published online: 22 December 2009

(C) The Author(s) 2009. This article is published with open access at Springerlink.com

\begin{abstract}
The adhesion (or available friction) in the wheel-rail contact is the most important parameter for the braking and traction operation of rail vehicles. Since the beginning of railway transportation, sanding from the locomotive has been a common practice to enhance the wheel-rail adhesion. In recent years, sanding from electrical multiple units (EMUs) and sand-based friction modifiers (FMs) have been adopted in some railway networks to overcome low adhesion incidents caused by leaf contamination in autumn. Although sanding has been proven to improve the adhesion under most of the typical contamination conditions, laboratory and field investigations have shown that sand may act as a solid lubricant in dry wheel-rail contacts. Nevertheless, the influence of the current sanding parameters on the solid lubrication effect has not been entirely investigated. Depending on the resulting adhesion coefficient, the traction and braking operations of rail vehicles could be affected. Furthermore, the influence of those parameters on the electrical insulation is also of special importance because it may affect the train detection. This article presents a laboratory investigation of the influence of three sanding parameters (i.e., feed rate, particle size, and slip) on the adhesion and electrical insulation in dry wheel-rail contacts. The tests have been carried out with a twin-disk roller rig in rollingsliding motion under closely controlled conditions. Three
\end{abstract}

O. Arias-Cuevas $(\bowtie) \cdot \mathrm{Z}$. Li

Section of Road and Railway Engineering, Faculty of Civil Engineering and Geosciences, Delft University of Technology, Stevinweg 1, $2628 \mathrm{CN}$ Delft, The Netherlands

e-mail: o.ariascuevas@tudelft.nl

R. Lewis

Department of Mechanical Engineering, University of Sheffield, Mappin Street, S1 3JD Sheffield, UK different slips representative of the actual traction and braking operations have been considered. Sands of four different sizes and up to five feed rates have been used. The results show that using smaller particle sizes and higher feed rates promotes the lubrication and causes more electrical insulation in the wheel-rail contact. Furthermore, the increase in slip is found to reduce the lubrication, leading to a higher adhesion coefficient.

Keywords Railroad · Rolling-sliding friction · Sand · Friction modifiers · Solid lubrication . Electrical insulation

\section{Introduction}

The friction between wheel and rail is a crucial factor in railway transportation, as it may limit the acceleration and braking capabilities of a train. The increasing demands in railway transportation have led to faster trains with higher accelerations and decelerations; however, the wheel-rail adhesion still remains limited by the available friction between the steel wheels and rails. Consequently, low adhesion problems have been present in many railway networks in recent decades, especially those related to leaf contamination in autumn [1-4]. Recent field investigations have demonstrated that leaf layers in dry conditions can lead to low adhesion incidents as well as in humid conditions [5]. Since the beginning of railways, sanding from the locomotive has been a common practice to enhance the wheel-rail adhesion [6]. In recent years, sanding from electrical multiple units (EMUs) has also been adopted in some railways to overcome low adhesion conditions $[1,7,8]$. Besides sanding, many railways have opted for using friction modifiers (FMs), some of which may contain sand 
or other solid particles to increase the adhesion level under certain contamination conditions [1, 4, 9].

Although railway sanding has been proven to improve the adhesion under most of the typical contamination conditions, laboratory and field investigations have shown that sand may act as a solid lubricant in dry wheel-rail contacts $[6,10-12]$. Lubricity is in the scope of this article identified with the reduction of the adhesion coefficient caused by sanding. Depending on the resulting adhesion coefficient, the traction and braking operations of rail vehicles could be affected. Andrews [6] investigated the adhesion values given by some mineral powders (silica sand among them) with a full-scale test bogie. He proposed an empirical relationship in which the adhesion coefficient increased proportionally with the product of particle hardness and size of the mineral powders. However, only one particle size was used for each mineral tested, and his empirical relationship was restricted to particle sizes smaller than $0.4 \mathrm{~mm}$. Kumar et al. [10] investigated in the laboratory the adhesion experienced by locomotive wheels during sanding and compared it to adhesion levels of dry clean contacts. They showed that the lubricant effect may only occur above a certain feed rate, but the feed rates of their study were below those used in current practice. They also showed that the adhesion coefficient increased with slip; however, only slip up to $1 \%$ was used in their study, which is below those found in braking and traction practice under low adhesion conditions. Boiteux et al. [11] presented the results of some braking tests performed in field under different contact conditions, in which the adhesion and wheel (gross-) slip were measured with two measuring wheelsets. They showed that sanding on rails covered by fallen leaves improved the adhesion, while sanding slightly reduced the adhesion on clean rails. Gallardo-Hernandez et al. [12] showed that sanding can help to overcome low adhesion caused by leaves and water, but it can decrease the adhesion in clean contacts. The findings of all those studies lead to the conclusion that feed rate, particle size, and wheel slip are the most influencing parameters on the solid lubrication effect of railway sanding. However, the influence of all those parameters was not investigated in a single study, and most of the investigations considered a range of parameter variation that does not correspond to the current sanding practice.

Furthermore, the most negative side effect of railway sanding is that it may insulate the electrical conductivity of the wheel-rail contact, depending on the amount of sand entrapped in the contact. The increase in electrical insulation is identified by the increase in the voltage across the wheel-rail contact due to sanding. In practice, if the voltage surpasses a certain threshold value, the functioning of the railway track circuits that are used for the detection of trains can be affected. Thus, the railway traffic signaling would be impaired, causing traffic disruption and perhaps, in the worst case, even collisions of trains. This has led railway organizations to establish standards on railway sanding that guarantee correct functioning of track circuits [13]. Lewis et al. [14, 15] investigated the electrical insulation of the wheel-rail contact caused by sanding in both static and dynamic tests. Their results showed that the electrical insulation of the wheel-rail contact varied with the sand feed rate, and complete electrical insulation may occur above a certain sand feed rate. Nevertheless, no study is found in the literature that considers the influence of the particle size and the wheel slip on the electrical insulation of the wheel-rail contact caused by sanding. This understanding becomes essential for an optimization of the sanding practice as correct train detection is of prime importance in railway transportation.

This article presents a laboratory investigation on the influence of the sand particle size, feed rate, and wheel slip on the lubricity and electrical insulation caused by railway sanding in dry contact conditions. The wheel-rail contact has been simulated in rolling-sliding conditions by means of a twin-disk roller rig under closely controlled laboratory conditions. During each test, the adhesion coefficient and the electrical voltage across the wheel-rail contact have been recorded. Four different sands have been used to account for the influence of the particle size. Three different slips representative of the actual traction and braking operations have been considered, and up to five feed rates have been applied in this study.

\section{Test Description}

\subsection{Test Setup}

The SUROS (Sheffield University ROlling Sliding) roller rig was used to simulate the wheel-rail contact in rollingsliding conditions. The SUROS roller rig is shown in Fig. 1 and described in detail in [16]. The test disks were mounted on independent shafts. By means of a hydraulic jack, a controlled load of $4.7 \mathrm{kN}$ was applied on the disks producing a maximum Hertzian pressure of $1.2 \mathrm{GPa}$ in the contact zone, which is representative of the contact between wheel tread and railhead for passenger trains in the Netherlands. Since cylindrical disks were used in the experiments, a line contact of $10 \mathrm{~mm}$-width was present (see Fig. 2). In the tests, the rotational speed of the rail was maintained at $400 \mathrm{rpm}$, equivalent to $0.98 \mathrm{~m} / \mathrm{s}$ of rolling speed. The wheel disk rotated faster than the rail disk to realize the slip. The slip is defined in Eq. 1, where $w$ and $r$ are the rotational speed and rolling radius of the disks, respectively. Tests were carried out at three different wheel slips, namely, 1, 5, and 10\%, which are typical values 
Fig. 1 Schematic representation of the SUROS roller rig setup

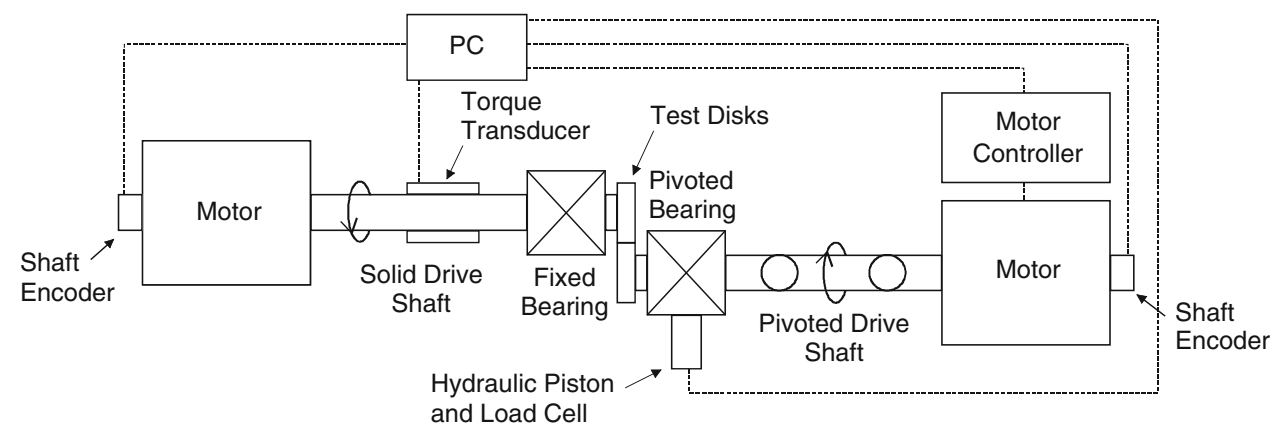

Fig. 2 Orientation and dimension of the disks

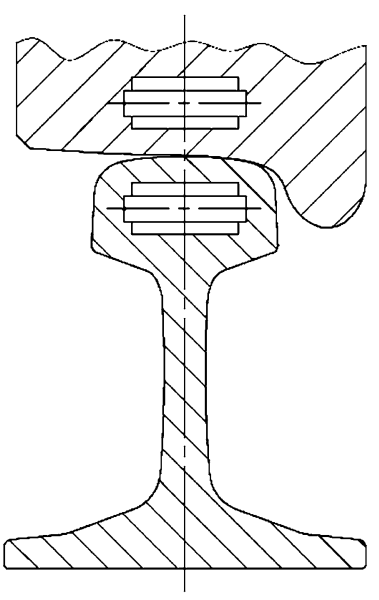

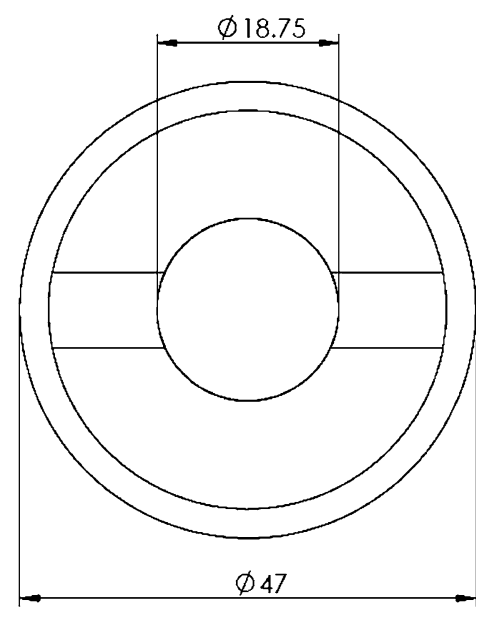

found in actual traction and braking operations. Considering the range of wheel slip used in the tests and the rolling speed of the rail disk, the mean rolling speed in the contact was between 0.99 and $1.07 \mathrm{~m} / \mathrm{s}$ in the tests. This low-speed regime is especially critical for those vehicles fitted with sanders that apply sand at a fixed rate in $\mathrm{kg} / \mathrm{min}$ as more sand is laid per length of rail.

A personal computer was used to acquire the data and to control both the speed and the load during each test. The adhesion coefficient was calculated with the readings of the torque transducer and the load cell, as indicated in Eq. 2, where $T$ represents the torque and $F_{\mathrm{N}}$ is the normal contact force. During calibration of the test rig, the uncertainty of the contact pressure was reported to be less than $\pm 2 \%$, while the standard error of the torque was found to be $0.30 \mathrm{Nm}$ [16]. Considering the values of the torque in this study, the maximum uncertainty in the torque readings was $\pm 2.72 \%$. Moreover, a hygrometer and a thermometer were placed next to the roller rig to monitor the ambient relative humidity and temperature in the tests. Measured values varied between 22 and $23.6{ }^{\circ} \mathrm{C}$ in temperature, and between 30 and $43 \%$ in relative humidity, which are values close to typical conditions of dry days.

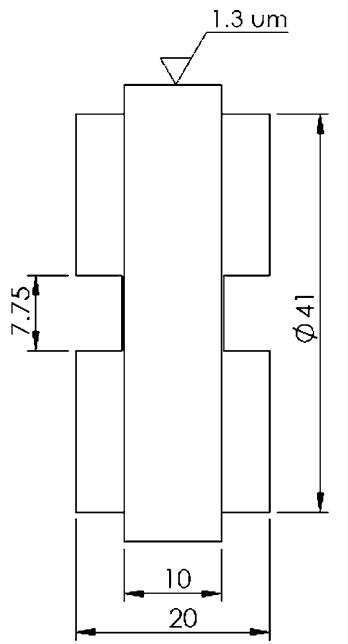

Slip $=\frac{w_{\text {wheel }} \cdot r_{\text {wheel }}-w_{\text {rail }} \cdot r_{\text {rail }}}{\frac{\left(w_{\text {wheel }} \cdot r_{\text {wheel }}+w_{\text {rail }} \cdot r_{\text {rail }}\right)}{2}} \cdot 100 \%$
$\mu_{\text {adhesion }}=\frac{T}{F_{\mathrm{N}} \cdot r_{\text {rail }}}$.

The test disks were cut from rails and wheel tires retired from service on the Dutch railway network, R260Mn and B5T steel for the rail and wheel disks, respectively. The disks were machined with their axes perpendicular to the longitudinal axis of both wheel and rail, as shown in Fig. 2 . The Vickers macro-hardness of the wheel and the rail steel used in the tests were measured as $267 \mathrm{HV}_{20 \mathrm{~kg}}$ and $281 \mathrm{HV}_{20 \mathrm{~kg}}$ on average, respectively. The roughness of the disks was measured with a profilometer, with an average value $1.3 \pm 0.2 \mu \mathrm{m}$. This value is close to the values of roughness measured with a Hommel tester on the running band of rails in field. Furthermore, the European standard for the manufacturing of wheels specifies that the initial surface roughness must be lower than $6.3 \mu \mathrm{m}$ on the running band on average [17]. However, laboratory investigations have shown that rough wheels tend to approach a roughness level close to the one of the smoother rails $[18,19]$. 
In order to monitor the electrical voltage across the disks contact area, an electrical circuit was installed on the roller rig so that voltage readings together with adhesion data could be obtained in the course of each test. Figure 3 depicts the electrical circuit, which had also been used for insulation studies on wheel-rail contacts in previous study [14]. In these tests, a nominal input voltage of $2 \mathrm{~V}$ was taken, but note that previous study demonstrated the negligible influence of the input voltage on the electrical insulation of the wheel-rail contact [14]. The accuracy of the voltmeter used to monitor Vout was $\pm 0.5 \mathrm{mV}$, which corresponds to a maximum uncertainty of $\pm 0.5 \%$ for Vout $\geq 0.1 \mathrm{~V}$. Owing to the position of the voltmeter in the setup, a so-called bearing resistance had to be included in the Vout readings, as indicated in Fig. 3. This resistance accounted for the lubricant circulating inside the bearing, but it could be neglected once sand was entrained into the disk interface as sand dominated the Vout readings. The Vout was recorded at a sampling frequency of $2 \mathrm{kHz}$, i.e., every $0.5 \mathrm{~mm}$ of travel distance of the rail disk, which corresponded to the length of the contact area in the rolling direction. The readings were further averaged to have 1 Vout reading per rail revolution (or cycle).

In the presence of an insulating contamination at the disk interface, the electrical resistance may become too high so that open circuit conditions occur, in which Vout $=1 \mathrm{~V}$. If the contact is not totally insulated, the voltage readings (in Volts) correspond to Eq. 3, in which $R c$ and $R b$ are the disks contact resistance and bearing resistance (in Ohms), respectively. In addition, a combined resistance of the total resistance seen by Vout, which is given by $R t=R c+R b$, could be used to simplify the formula.

$$
\begin{aligned}
\text { Vout } & =\frac{10 \cdot(R c+R b)}{10+R c+R b} \cdot \frac{2}{10+\frac{10 \cdot(R c+R b)}{10+R c+R b}} \\
& =\frac{10 \cdot(R t)}{10+R t} \cdot \frac{2}{10+\frac{10 \cdot(R t)}{10+R t}} .
\end{aligned}
$$

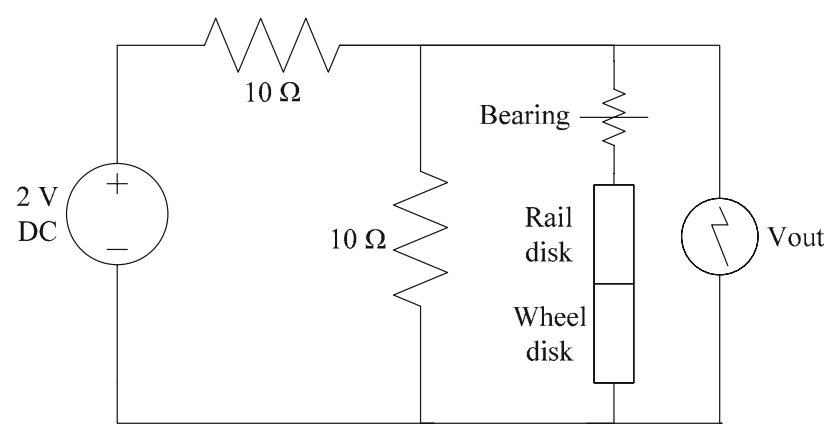

Fig. 3 Schematic representation of the electrical circuit

\subsection{Tested Sands}

Two types of commercial sand were used in this study: silica sand and filter sand. The silica sand had been extracted from a pit in South Germany, whereas the filter sand had been collected from a river in The Netherlands. A photograph of the sands is given in Fig. 4. The particle size distribution of the sands was measured with a laser particle analyzer and is given Fig. 5. The filter sand is the standard type used in the Netherlands to increase the adhesion in railways; thus, it is hereinafter referred to as Railway sand, $\mathrm{R}$ sand in short. Although different rocks can be seen in the sample, the weight content in $\mathrm{SiO}_{2}$ is around $96 \%$ as given by the supplier. The particle size distribution of $\mathrm{R}$ sand ranged from 0.25 to $1.4 \mathrm{~mm}$ with a wide peak at 0.6 $1 \mathrm{~mm}$, as shown in Fig. 5. The silica sand had a $\mathrm{SiO}_{2}$ content around $99 \%$ according to the supplier. It was sieved in the laboratory to three different particle size ranges: small $(0.06-0.3 \mathrm{~mm}$, with peak at $0.15 \mathrm{~mm})$, medium $(0.3-$ $0.6 \mathrm{~mm}$, with peak at $0.35 \mathrm{~mm})$, and large $(0.85-1.6 \mathrm{~mm}$, with peak at $1.2 \mathrm{~mm}$ ). These three sands are referred in this article as S sand, M sand, and L sand, in short. Moreover, due to the similar composition and hardness of the four tested sands, the particle size distribution could be considered as the only study parameter for this study.

\subsection{Test Procedure}

In the tests, the sand was fed to the disk interface by means of gravity, as shown in Fig. 6. After exiting the valve, the sand passed through a PVC pipe and was oriented to the disk interface with a chute. A vacuum cleaner placed behind the disks sucked the sand into the wheel-rail contact, which simulated the compressed air system used in reality. Two funnels helped the sand feed to the PVC pipe. In order to regulate the sand feed rate, plastic syringes were used as valves. The orifice had to be modified to achieve the desired feed rate. The different particle size distributions of the four sand types required different orifice sizes because of their different bulk densities. Up to five sand feed rates were used in the testing, namely, FR $1=0.75 \mathrm{~g} / \mathrm{m}, \mathrm{FR} 2=1.5 \mathrm{~g} / \mathrm{m}$, $\mathrm{FR} 3=3 \mathrm{~g} / \mathrm{m}, \quad \mathrm{FR} 4=4.5 \mathrm{~g} / \mathrm{m}, \quad \mathrm{FR} 5=7.5 \mathrm{~g} / \mathrm{m}$. In the calculation of these feed rates, the rolling speed and traveled length of the rail disk are taken as reference. Note that FR5 is representative of some feed rates used in practice [20].

Figure 7 depicts a generic test with two outputs: adhesion coefficient and Vout. Each single test was run with a new pair of disks and a fixed slip. Several sand applications were undertaken within one test to reduce the total number of separate tests. Each sand application lasted for around 60 cycles, and some cycles between each sanding were left to account for the run-in of the disk surfaces, as shown in 
Fig. 4 Photograph of the tested sands: $\mathrm{S}$ sand, $\mathrm{M}$ sand, $\mathrm{L}$ sand, $\mathrm{R}$ sand

Fig. 5 Particle size distribution of the tested sands obtained with the laser particle analyzer
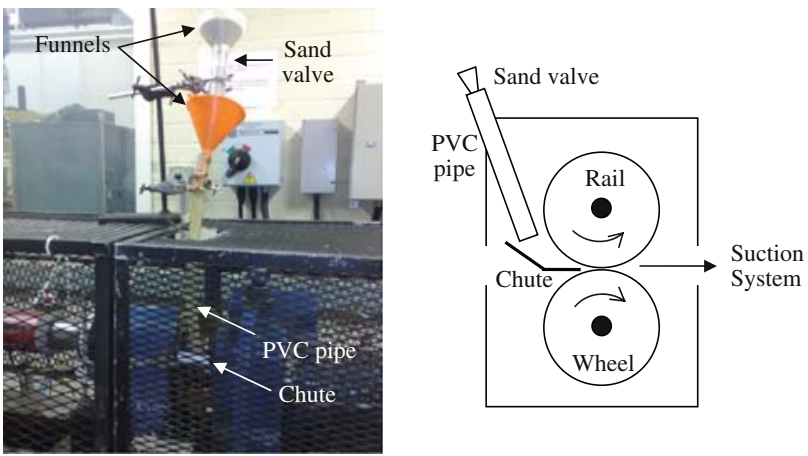

Fig. 6 Sand application method: photograph (left) and schematic (right)
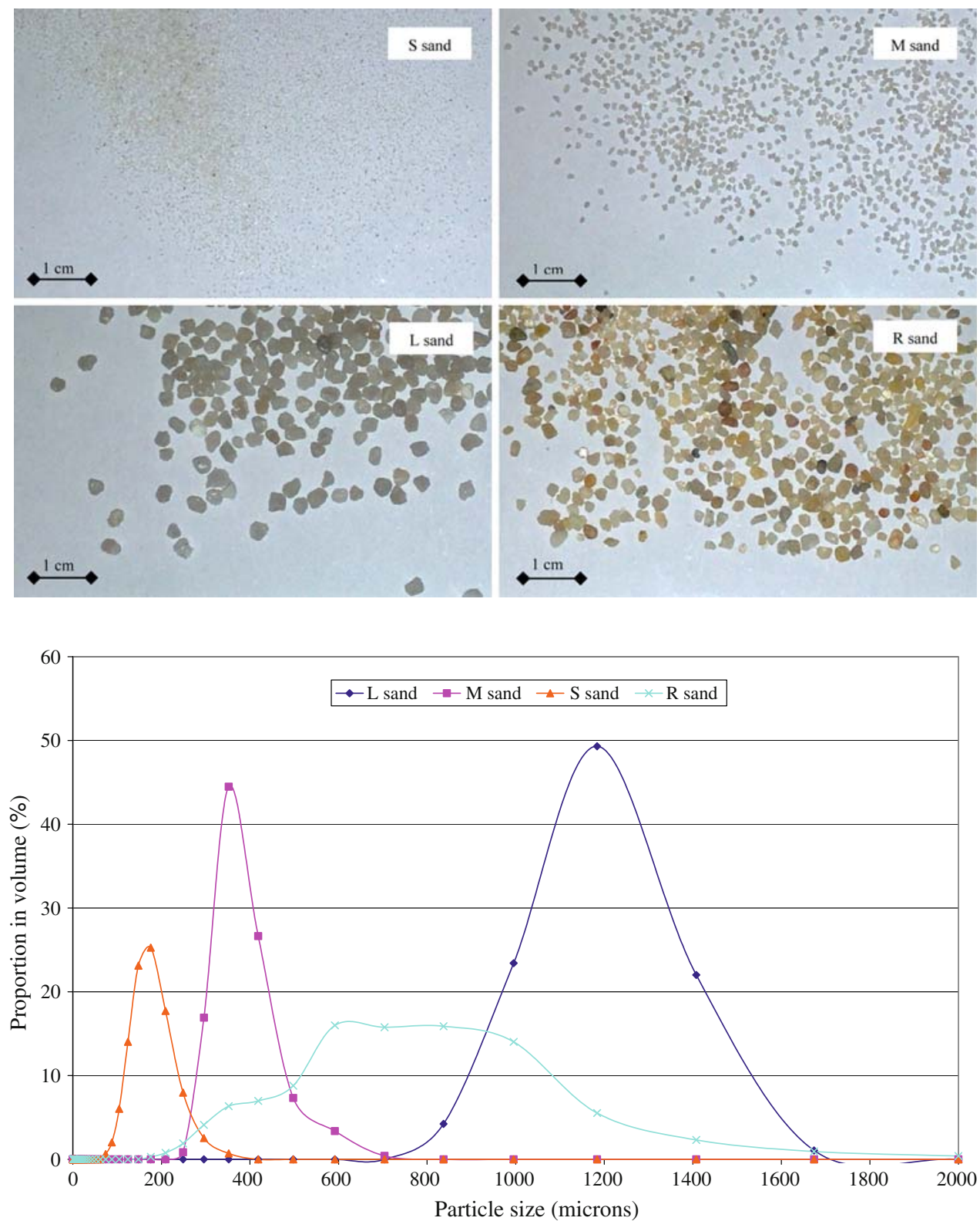

Fig. 7. Thus, the adhesion coefficient (and correspondingly the condition of the surfaces) was always around the same level at the start of each sand application so that the results of different sand applications were comparable in one test.

On the basis of the Vout readings, two regimes of lubrication could be identified during sanding, which are designated in this study as partial lubrication and full lubrication. In partial lubrication regime, there existed some metal-metal contact between asperities leading to readings of Vout below $1 \mathrm{~V}$, but due to the presence of sand particles, the Vout readings were higher than those of pure metal-metal contact, as shown in Fig. 7. In the full lubrication regime, enough sand entrained the contact to separate the surfaces of wheel and rail disks, leading to 
Fig. 7 Generic test with several sand applications in one test

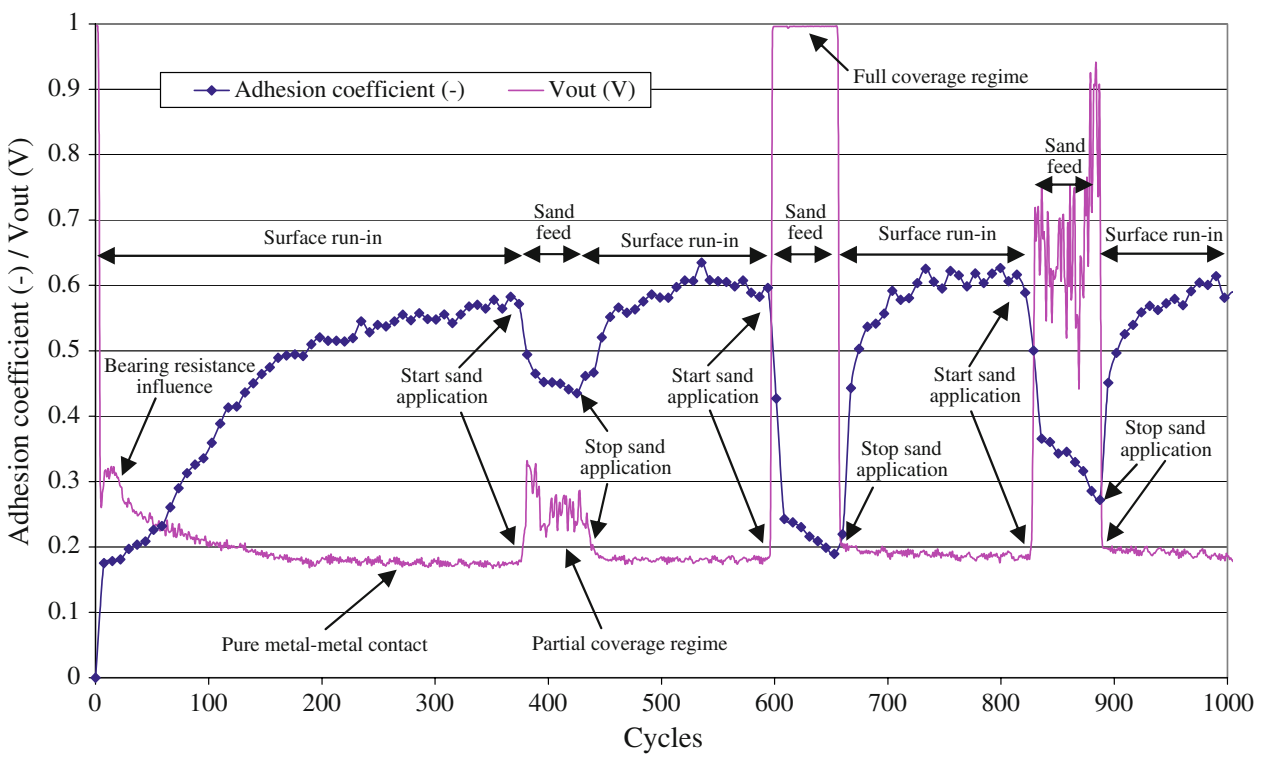

open-circuit conditions. Therefore, increasing the amount of sand entrained in the contact resulted in a transition from partial lubrication to full lubrication regime.

The tests were aimed at investigating the influence of the feed rate and the particle size on both adhesion and electrical insulation at different slips. In order to analyze the influence of the feed rate, $S$ sand was applied at five different feed rates, i.e., from FR1 to FR5 in increasing order. S sand was chosen due to its small particle size that allowed for low feed rates before clogging. On the contrary, the influence of the particle size was investigated by applying each of the tested sands at FR5 in the following order: L, M, R, and S sand. Furthermore, all the tests were repeated at 1,5 , and $10 \%$ slip, so that the influence of the wheel slip on lubricity and electrical insulation could also be analyzed.

\section{Results}

\subsection{Feed Rate Tests}

The adhesion and electrical insulation results of the feed rate tests are given in Figs. 8, 9, 10 (note that the order of application was from FR1 to FR5 in the tests). As it was expected, the entrapment of sand in the disk interface caused an increase in the electrical insulation of the wheelrail contact. In the tests, the transition from partial lubrication to full lubrication could be observed as the feed rate increased. Open-circuit conditions, and thus full lubrication regime, were reached for the highest feed rate, as indicated in Fig. 8. Furthermore, once sand particles were entrained into the disk interface, the adhesion instantly dropped for all the slips and feed rates tested, corroborating the solid lubrication caused by S sand in dry contacts. One striking phenomenon was observed during the sand feed. Besides the instantaneous reduction of adhesion due to the initial sand entrapment, the adhesion coefficient continued to decrease as the sand feed progressed, as shown in Fig. 8. This second adhesion reduction phenomenon could be attributed to the formation of a coating of compacted, embedded, crushed sand on the wheel and rail disk surfaces. The coating formation during continuous sanding was also observed in another study of the authors [21]. In order to distinguish between these two phenomena, we refer to them hereinafter as initial and continuous adhesion reduction.

The continuous adhesion reduction phenomenon was particularly noticeable at low slips (see Fig. 8), whereas it occurred to a lesser extent at higher slips (see Fig. 10). This can be explained by the increased abrasion caused at higher slips, which may have hindered the coating formation. This is in agreement with observations in other study [21]. On the contrary, the feed rate showed some influence on this phenomenon, which was particularly visible in the tests at $5 \%$ slip. Higher feed rates were found to promote the continuous adhesion reduction, which could be attributed to the increased flooding of particles through the contact that may effectively reduce the abrasion, promoting the coating formation. Moreover, it can be observed that less number of cycles was needed to complete the tests at high slips. This was expected because the increase in slip can enhance the run-in of the disks surfaces so that fewer cycles between sand applications were necessary at higher slip.

In Fig. 11, the average adhesion coefficient registered during the sand feed is given as a function of the feed rate, in which the data points have been connected by straight 
Fig. 8 Adhesion and conductivity results during feed rate test with $\mathrm{S}$ sand at $1 \%$ slip (order: from FR1 to FR5)

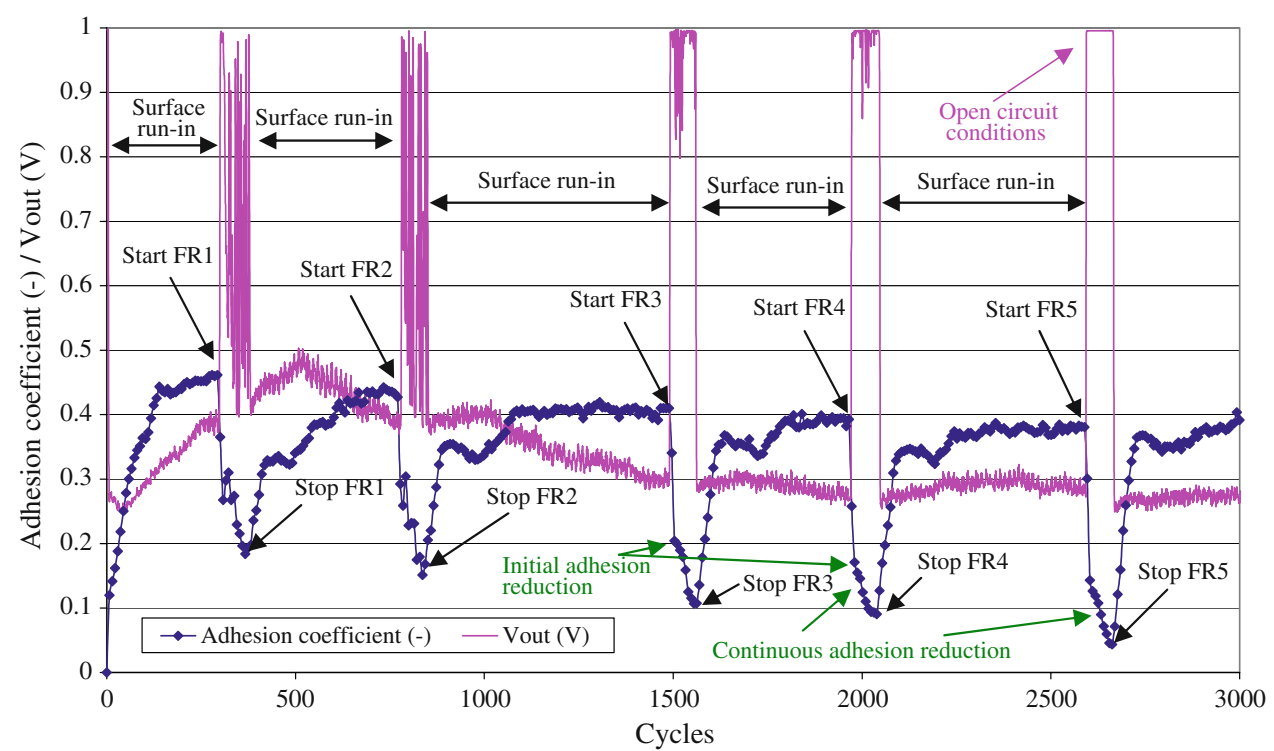

Fig. 9 Adhesion and conductivity results during feed rate test with $\mathrm{S}$ sand at $5 \%$ slip (order: from FR1 to FR5)

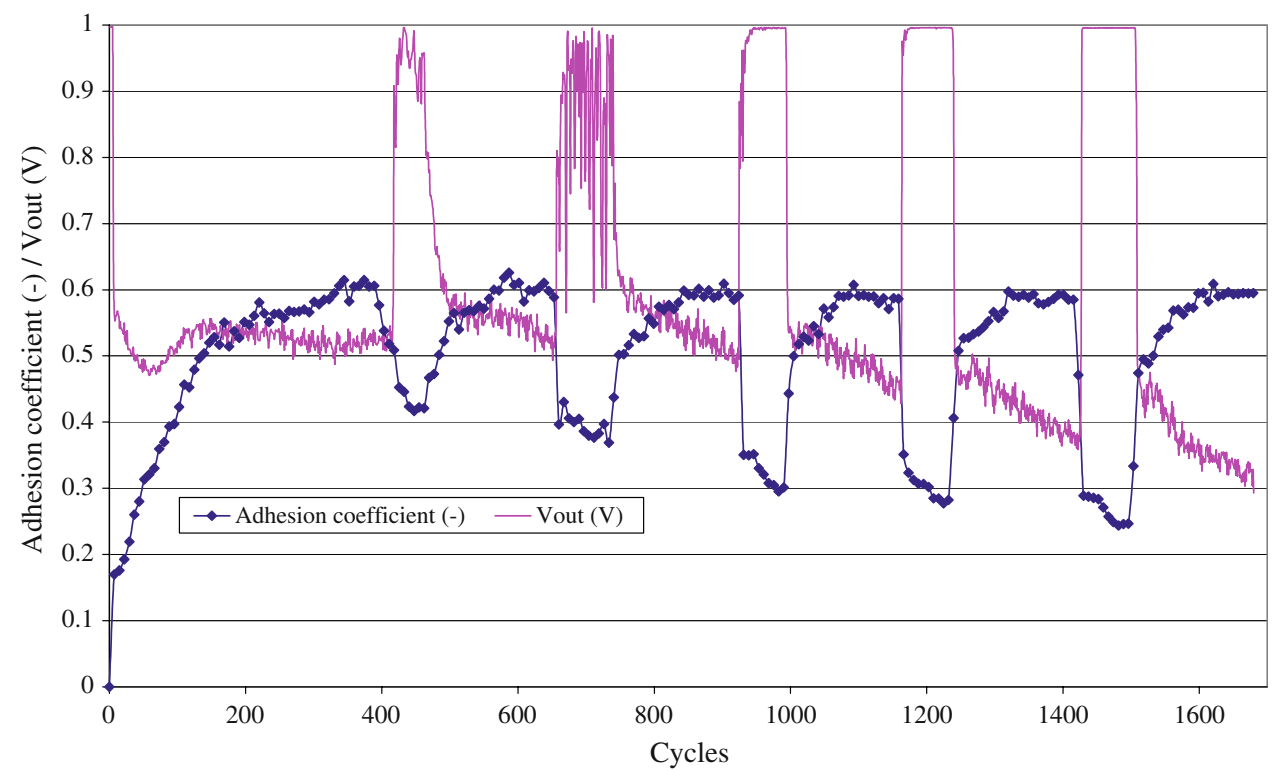

lines. Note that the values at null feed rate correspond to those of the dry metal-metal contacts, which correspond to a traction curve in dry contacts. It can be observed that the adhesion coefficient decreased with the increase of feed rate for all the slips tested. The increase in feed rate led to more particles in the contact, which could partly bear the contact load and accommodate some of the slip, leading to an increase in the lubricating effect in the partial lubrication regime. Above a certain feed rate, full lubrication regime was reached, which could be identified with the open-circuit conditions. Further increase in the feed rate from this point on could have led to more particles free to move relative to each other, promoting the decrease in the adhesion coefficient. In addition, it can be seen in Fig. 11 that the increase in slip resulted in higher adhesion coefficients for all the feed rates applied. This means that the longer sliding distances traveled by the (crushed) sand particles over the disk surfaces may have enhanced the interlocking action between the disk surfaces. This interlocking mechanism has been identified as responsible of the friction force obtained in the wheel-rail contact during sanding [22].

The increase in the wheel-rail electrical insulation (in average) during the sand feed at different feed rates and slips is displayed in Fig. 12. The feed rate was found to have an important effect on the electrical insulation, where higher feed rates led to more electrical insulation. This was expected as increasing the number of particles present at the disk interface can lead to the transition from partial lubrication to full lubrication regime. In general, the 

conductivity results during feed rate test with $\mathrm{S}$ sand at $10 \%$ slip (order: from FR1 to FR5)
Fig. 10 Adhesion and

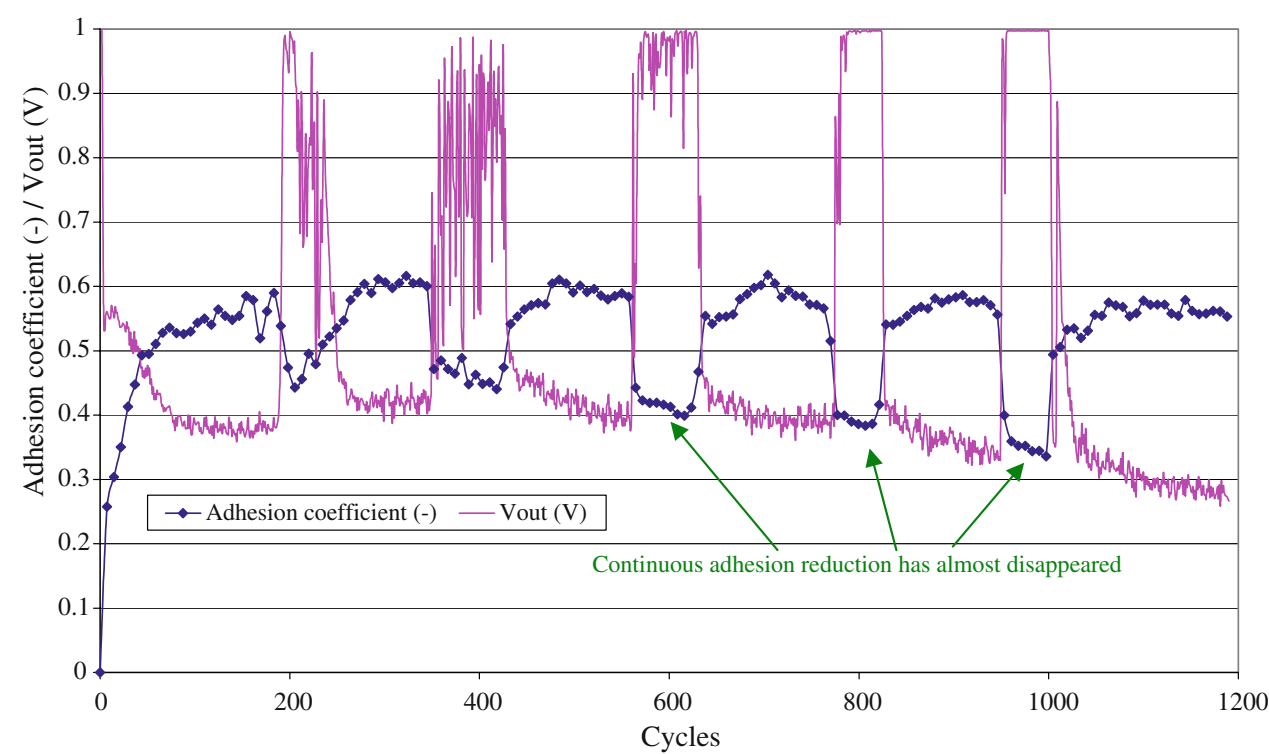

Fig. 11 Average adhesion coefficient during feed of S sand at different slips and feed rates in dry contacts

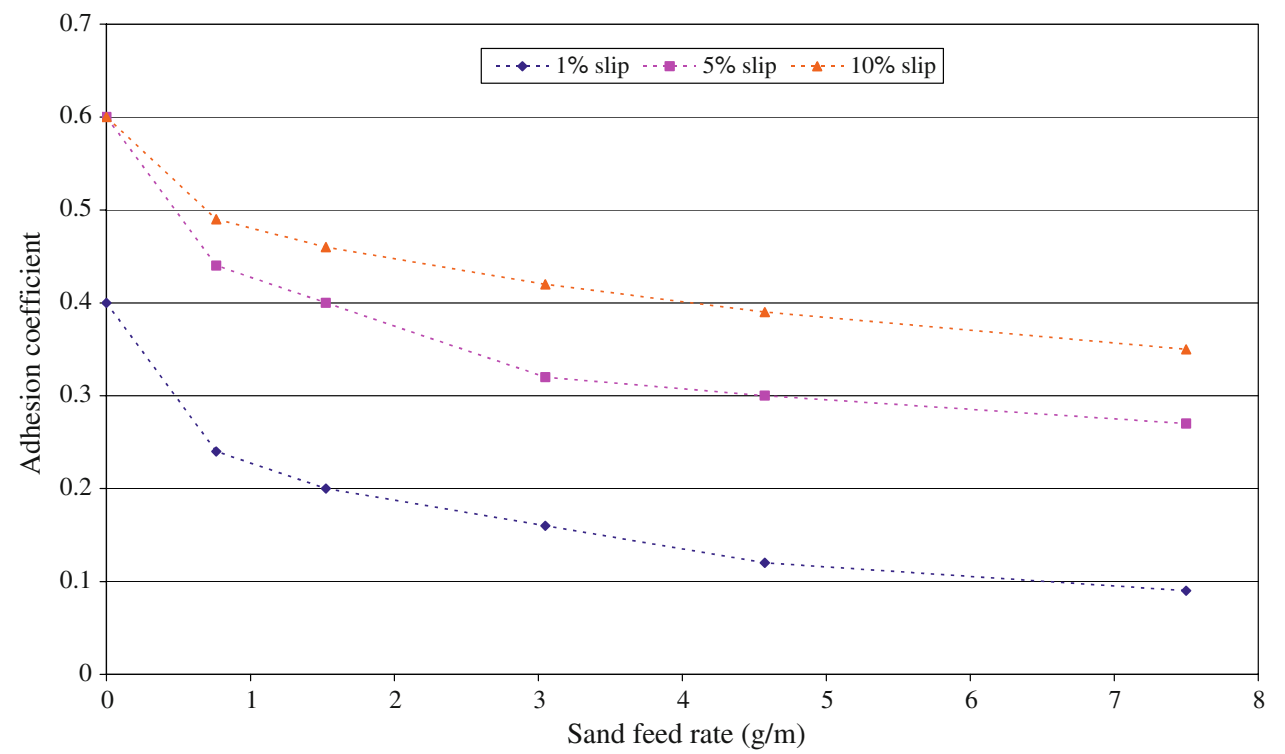

particles may agglomerate at the disk interface to form a third-body layer, whose electrical insulating properties increase the voltage across the disk contact area. Furthermore, the slip seemed to cause an increase in the Vout at low feed rates. This could indicate that the particle entrapment at the disk interface was somewhat promoted by higher slips at those feed rates.

\subsection{Particle Size Tests}

The adhesion and electrical insulation results of the particle size tests are given in Figs. 13, 14, 15. In these tests, the sand was fed at rate FR5, as representative of rates used in practice. Note that the order of sand application was arbitrarily chosen as: $\mathrm{L}, \mathrm{M}, \mathrm{R}$, and $\mathrm{S}$ sand. It can be seen that the electrical insulation of the wheel-rail contact increased due to the sand entrapment for all the sands tested, but open-circuit conditions were only experienced with $\mathrm{S}$ and $M$ sand as shown in Fig. 13. On the contrary, the solid lubrication effect of sanding was observed with all the sands and slips used. Furthermore, the continuous adhesion reduction as the sand feed progressed (previously outlined in the feed rate tests) also occurred in these tests, especially at low slips (see Fig. 13).

In Figs. 13, 14, 15, it can be seen that the adhesion reduction was dependent on the particle size and the particle size distribution. By comparing the results of the three sands of similar particle size distribution but different sizes (i.e., $\mathrm{S}, \mathrm{M}$, and $\mathrm{L}$ sand), it could be seen that increasing the particle size could hinder the continuous adhesion reduction 
Fig. 12 Increase in average Vout during feed of $\mathrm{S}$ sand at different slips and feed rates in dry contacts
Fig. 13 Adhesion and conductivity results during particle size test at $1 \%$ slip (order of application: L, M, R, and $\mathrm{S}$ )
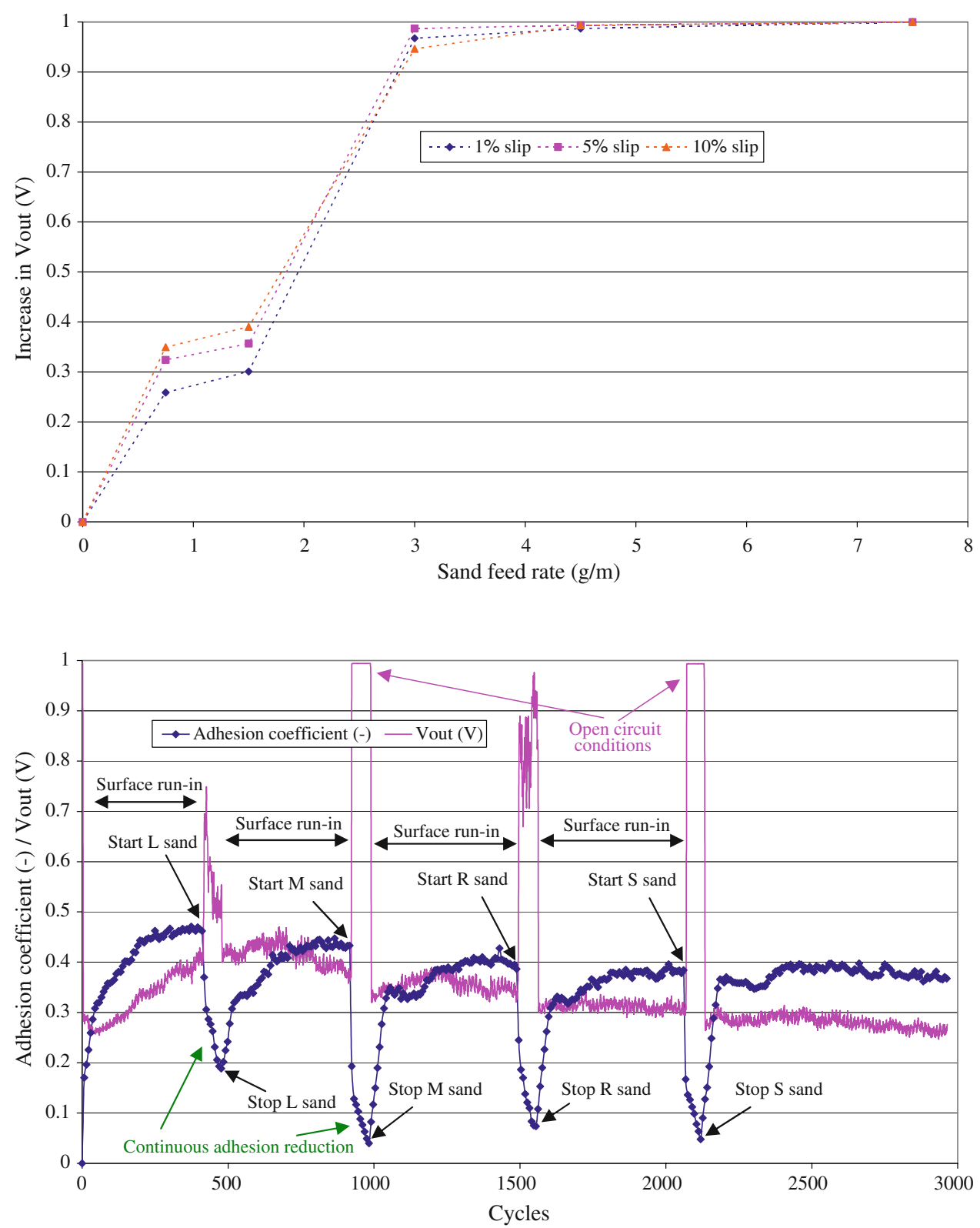

effect. This could have two possible explanations: first, less volume of sand traveling through the contact when using larger particle sizes, leading to less lubrication; second, deeper abrasion could be expected with larger particles. Moreover, the continuous adhesion reduction was especially noticeable with $\mathrm{R}$ sand, which could be caused by its broad particle size distribution. In another study, [21] the authors observed notable oscillations of the adhesion coefficient in tests with R sand, which seemed to be partly caused by the continuous process of formation and breakup of the coating on the disk surfaces. Hence, the authors would expect that if the sanding of these tests was continued further than 60 cycles, then the adhesion coefficient may have increased again and continued to oscillate. This was, however, not examined in this study. Finally, it is worthwhile to mention that the adhesion coefficient and Vout results obtained with S sand at FR5 in Figs. 8, 9, 10 and $13,14,15$ matched very well, which demonstrated the consistency of the test results.

Figure 16 depicts the average value (together with the maximum and minimum values) of the adhesion coefficient during the sand feed of all the tested sands at the three slips applied. It can be seen clearly that the influence of the sand particle size on the adhesion coefficient had a consistent tendency for all the slips, which appeared to be curvilinear with a trough at $\mathrm{M}$ sand as indicated by the trendlines of Fig. 16. Hence, higher adhesion coefficients were obtained when using larger particle sizes for the range M-L sands. On the contrary, the tendency of increasing adhesion coefficient with particle size distribution was reversed in 
Fig. 14 Adhesion and conductivity results during particle size test at 5\% slip (order of application: L, M, R, and $\mathrm{S}$ )

Fig. 15 Adhesion and conductivity results during particle size test at $10 \%$ slip (order of application: L, M, R, and $\mathrm{S}$ )
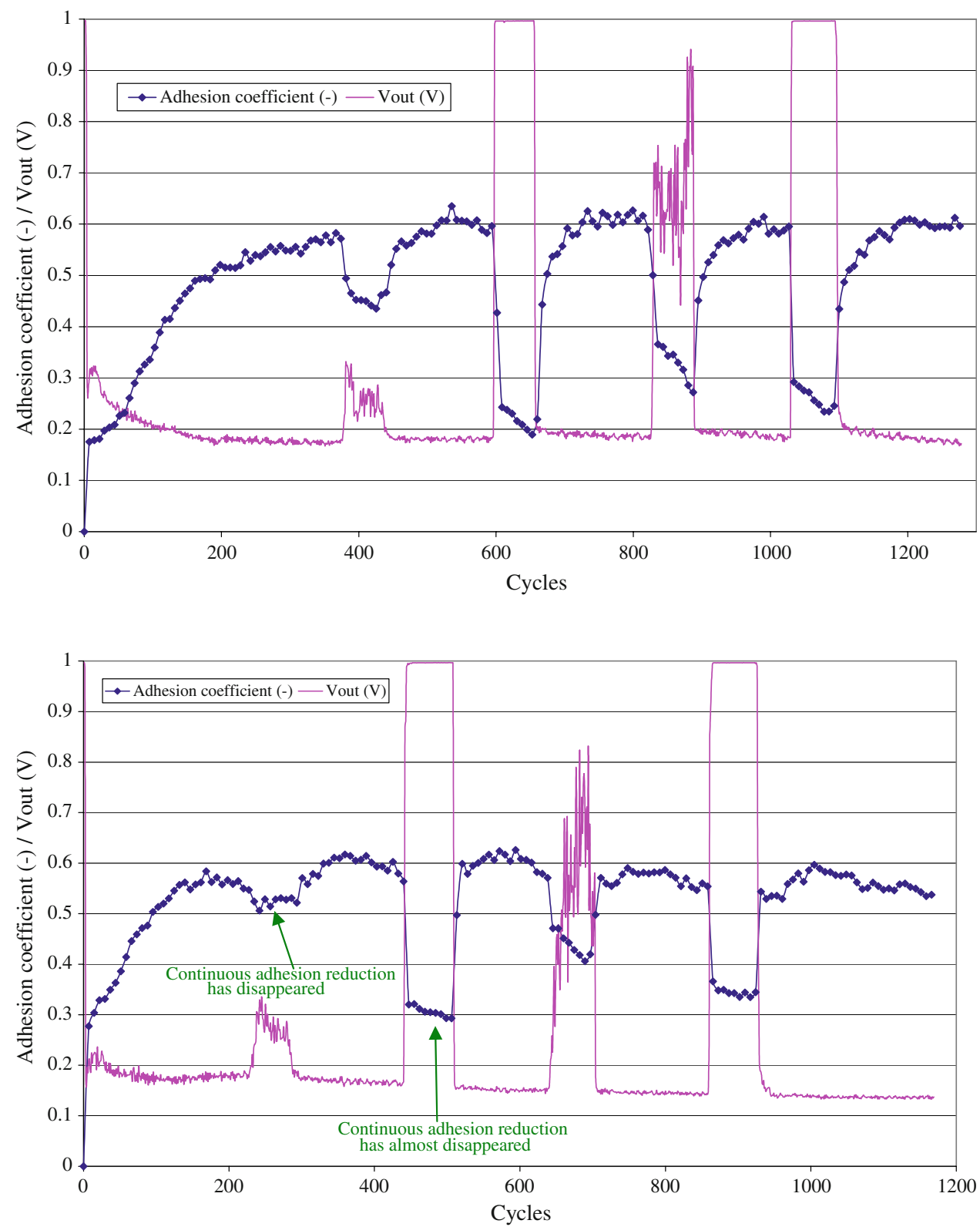

the smaller particle size range $\mathrm{S}-\mathrm{M}$ sands. No explanation has been found for this result, and further investigation with more sand sizes in the small particle size range should be performed to draw solid conclusions. Moreover, it can be seen that the increase in slip led to an increase in the adhesion coefficient for all the sands tested, which is in line with the observations on the feed rate tests with $\mathrm{S}$ sand (see Fig. 11).

The electrical insulation was found to be largely dependent on the particle size of the sand used, as shown in Fig. 17. Smaller particle sizes of sand caused more electrical insulation than larger sands, leading to open circuit conditions with $\mathrm{M}$ and $\mathrm{S}$ sands. In the tests with $\mathrm{R}$ and $\mathrm{L}$ sands, Vout increased compared to the clean contact conditions, but no open-circuit conditions were reached. However, R sand caused more electrical insulation than L sand, which is ascribed to its smaller particle size. Figure 18 depicts a schematic representation of the particle entrapment experienced by sands of different particle sizes. In general, the largest particles present in the contact break up first to form a sufficient number of particles that can bear the contact load. Some broken particles enter the disk interface, while some are ejected. When using smaller sized sand, more particles can enter the contact without being broken up. Therefore, the electrical insulation threshold in sanding is not only dependent on the feed rate but also on the particle size. Although it has been shown that the insulation threshold is to be found at lower feed rates when using smaller particles (see Figs. 12 and 17), no detailed quantitative study has been carried out in this study. 
Fig. 16 Average adhesion coefficient (together with max and min values) during feed of different sands at different slips in dry contacts. Full bars = complete insulation

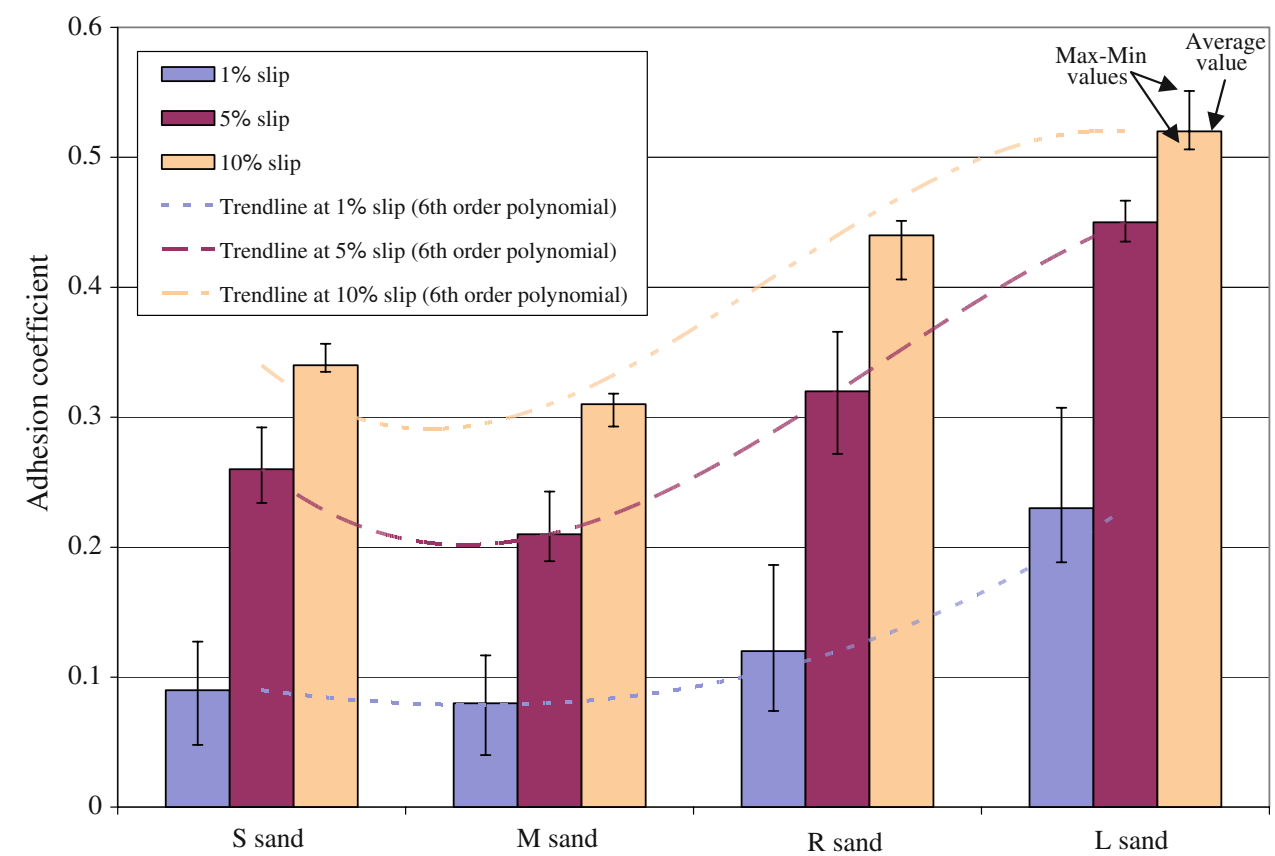

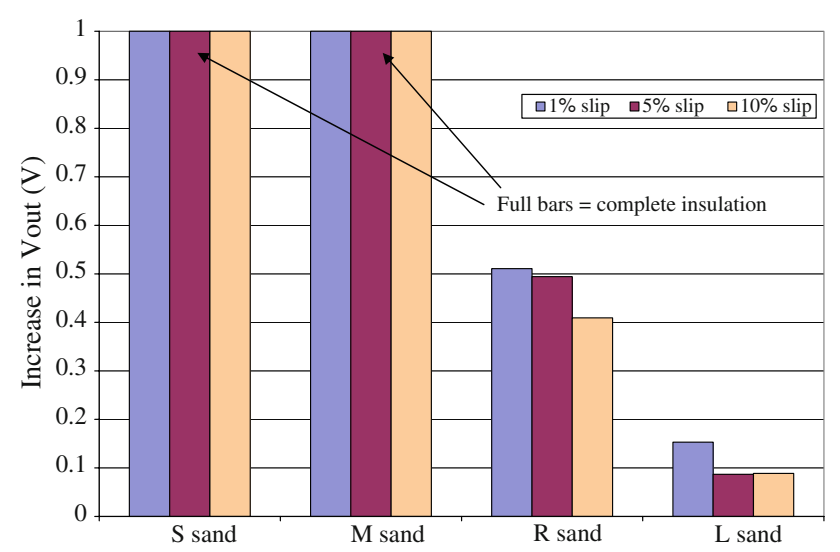

Fig. 17 Increase in Vout (in average) during feed of different sands at different slips in dry contacts

Moreover, a different influence of the slip on the electrical insulation was observed in these tests compared to the feed rate tests with S sand. It can be seen in Fig. 17 that the increase in slip seem to cause less electrical insulation in the wheel-rail contact for R and L sands, which may be attributed to the less coating formation occurring at higher slips. This can be examined by looking at the continuous adhesion reduction phenomenon pointed in Figs. 13, 14, 15. Hence, the possible enhancement of particle entrapment with the slip could not be observed in these tests.

\section{Discussion}

The results of this study showed that for all the particle sizes, feed rates, and slips, sand acted as a solid lubricant in dry wheel-rail contacts. Kumar et al. [10] showed that the lubrication effect of sanding was not observed below a transition feed rate identified as around $0.75 \mathrm{oz} / \mathrm{min}$ in their setup. If one considers the differences in contact geometry and rolling speed between their setup and the one used for this study, then their transition feed rate can be calculated to be between 0.167 and $0.33 \mathrm{~g} / \mathrm{m}$, depending on the evolution of their contact area width. Therefore, in our study, we could never have seen that effect of higher adhesion with sand than in dry steel-on-steel contact because our minimum feed rate tested was $0.75 \mathrm{~g} / \mathrm{m}$. Note that there are other differences in both test setups that complicate a
Fig. 18 Schematic representation of the possible sand entrapment with different particle sizes

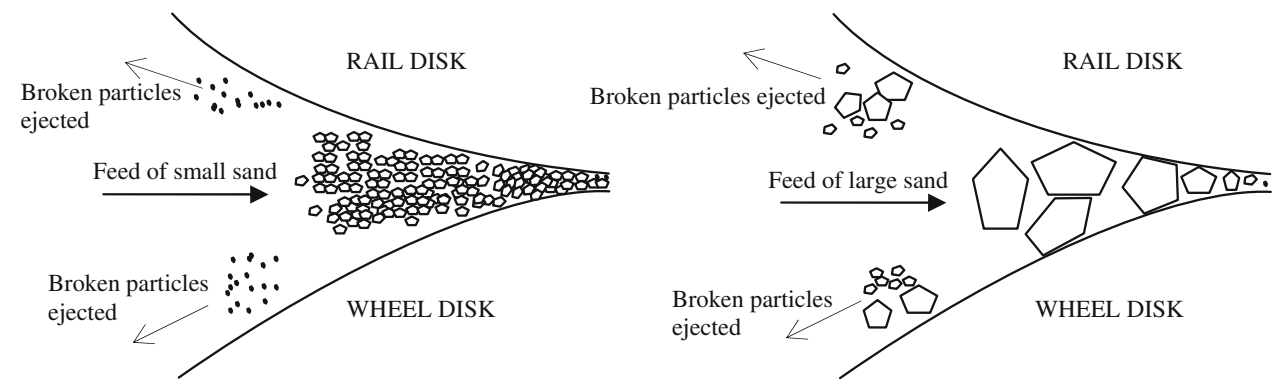


quantitative comparison such as the sand particle size, the contact area dimensions, the roller rig characteristics, and the contact pressure.

In both locomotives and EMUs, railway sanding is often activated automatically by the wheel slide protection and traction control systems, which trigger the sand application once the wheel slip is found to have passed a certain threshold according to existent specifications [7]. This study has shown that there is a strong influence of the wheel slip on the adhesion coefficient yielded by sanding, which shows that higher adhesion coefficients are obtained at higher slips for all the sand particle sizes of these tests. In another study, the authors have shown that the slip greatly affects the wear rates of wheels and rails during sanding, with higher wear rates at higher slips [21]. Hence, further investigations in field may be encouraged to find the optimum slip that can yield an adhesion coefficient suitable for traction and braking operation, without compromising admissible wear rates of wheels and rails.

Sand-based FMs and railway sanding are used in some railway networks to guarantee an adhesion level suitable for traction or braking operation. On the contrary, if not properly applied, they may also cause very high friction, leading to excessive wear or rolling contact fatigue (among others). The results of this study indicate that an appropriate combination of particle size, feed rate, and slip could be found to yield an optimal adhesion level. In particular, it has been shown that by decreasing the particle size of the sand, lower feed rates are necessary to obtain the same adhesion level than with larger particles. This may increase the interval required to refill the sand boxes, reducing the costs of sanding operation. In order to examine the possible optimization of sanding practice, the authors have also carried out an investigation on wear and adhesion recovery in leaf contaminated contacts [21, 23].

In this study, the feed rate and particle size have been found as the main parameters affecting electrical insulation during sanding. Higher feed rates and smaller sand particles have been shown to insulate more the electrical conductivity of the wheel-rail contact. Since this electrical conductivity is used in practice for the track circuits of the train detection system, special importance must be given to the identification of the critical sand feed rate for a chosen particle size distribution so that the train operation is not disturbed during sanding.

In practice, the sanders are not fitted on all the axles of a train so that the amount of sand laid on the rails is first used by the wheels of sanding axles, while the following wheels roll over the remaining crushed sand. Hence, the results obtained in this study are related to the wheels of sanding axles, and in particular to the first sanding wheelset in the traveling direction. One of the limitations of this testing is that the infinite rail has been simulated with a disk so that every cycle on the wheel surface comes in contact with an already sand-treated rail surface. This circumstance may have been responsible for the continuous adhesion reduction effect, which was especially observed at low slips. At higher slips, the removal of crushed sand from the rail surface is increased, so that the effect of the rail surface treatment is diminished.

In wet contacts, the behavior of sand entrapment may be different from what is described in this study. Previous study showed higher adhesion coefficient when sanding is carried out in wet contacts compared to sanding under dry conditions [20]. This could be explained by the capillary action of a water film, which can promote the particles entrapment, particularly with the larger particles where fractured bits of sand are pulled into the contact as they adhere to the disk surfaces. This different entrapment mechanism can thus affect the electrical insulation and adhesion. Since sand is more likely to be applied in wet conditions, the possible influence of water on the results presented in this article may be interesting for further studies.

Furthermore, there are several differences that impede a direct comparison of the results of this testing with the actual situation in railway sanding. There exists a considerable geometrical scaling between the test setup and the actual wheel-rail contact. In particular, the wheel and rail disks used in the testing had a finite rolling radius of $23.5 \mathrm{~mm}$, while actual wheels and rails have a rolling radius of $460 \mathrm{~mm}$ and infinity, respectively. This geometrical difference could have led to a different particle entrapment compared to the actual situation. In addition, the length of the contact area in the rolling direction was $0.5 \mathrm{~mm}$ in these tests, which may be smaller than some of the (crushed) sand particles traveling through the disk interface, leading to a different behavior. Moreover, more sand could have been entrained than in practice because in this testing, the sand was directly applied to the disks contact in the absence of crosswind and train's slipstream. Therefore, the results given in this article can only be taken so far as indicative of what happens in the actual wheel-rail contact. Future study should aim at determining the scaling factors so that quantitative relationships between the twin-disk testing and actual operation conditions can be established.

\section{Conclusions}

A laboratory investigation on the influence of three railway sanding parameters (i.e., feed rate, particle size, and wheel slip) on the adhesion and electrical insulation has been presented in this article. The wheel-rail contact has been simulated by means of a twin-disk roller rig in rolling-sliding 
conditions. Three different slips have been considered in the testing that are representative of actual traction and braking operations of railways. Four different sizes of sand have been used to investigate the influence of the particle size. Up to five different feed rates have been applied in the testing to analyze their effects. On the basis of the results obtained in this study, the following conclusions can be drawn.

(a) Sand acts as a solid lubricant for all the tested particle sizes, slips, and feed rates in dry wheel-rail contacts.

(b) Using larger particle size of sand generally yields higher adhesion coefficient and causes less electrical insulation in the wheel-rail contact.

(c) Higher feed rates lead to lower adhesion coefficient and more electrical insulation.

(d) The increase in slip enhances the interlocking action of sand so that higher adhesion coefficients are obtained.

(e) An optimal adhesion coefficient may be achieved with a suitable combination of particle size, feed rate, and wheel slip.

Acknowledgments The authors thank Dr. Beto Gallardo-Hernandez from the Mechanical Department of The University of Sheffield for his support in preparing the test setup. This article is especially dedicated to the memory of Dr. Mike Frolish, not only for his contribution to this particular study but also for his remarkable support in all the work carried out with the SUROS roller rig by the authors.

Open Access This article is distributed under the terms of the Creative Commons Attribution Noncommercial License which permits any noncommercial use, distribution, and reproduction in any medium, provided the original author(s) and source are credited.

\section{References}

1. Fulford, C.R.: Review of low adhesion research. Report published by the Rail Safety and Standards Board, UK (2004)

2. Olofsson, U., Sundvall, K.: Influence of leaf. humidity and applied lubrication on friction in the wheel-rail contact: pin-ondisc experiments. J. Rail Rapid Transit. 218, 235-242 (2004)

3. Cann, P.M.: The 'leaves on the line' - a study of leaf residue film formation and lubricity under laboratory test conditions. Tribol. Lett. 24, 151-158 (2006)

4. Li, Z., Arias-Cuevas, O., Lewis, R., Gallardo-Hernandez, E.A.: Rolling-sliding laboratory tests of friction modifiers in leaf contaminated wheel-rail contacts. Tribol. Lett. 33, 97-109 (2009)

5. Arias-Cuevas, O., Li, Z.: Field investigations on the adhesion recovery in leaf contaminated wheel-rail contacts with locomotive sanders. Submitted for publication (2010)
6. Andrews, H.I.: Railway Traction-The Principles of Mechanical and Electrical Railway Traction. Elsevier, Amsterdam (1986)

7. Sanding Equipment Fitted to Multiple Units and On-track Machines. Railway Group Standard GM/RT 2461 (2001)

8. Voges, W., Spiess, P.: Optimizing Services with EMU ET42x in Autumn 2004 and 2005. In: Proceedings of 7th World Congress on Railway Research, Canada (2006)

9. Arias-Cuevas, O., Li, Z., Lewis, R., Gallardo-Hernandez, E.A.: Rolling-Sliding Laboratory Tests of Friction Modifiers in Dry and Wet Wheel-Rail Contacts. Wear (2009). doi:10.1016/j.wear. 2009.09.015

10. Kumar, S., Krishnamoorthy, P.K., Prasanna Rao, D.L.: Wheelrail wear and adhesion with and without sand for a North American locomotive. J. Eng. Ind. 108, 141-147 (1986)

11. Boiteux, M., Cadier, M., Kling, J., Kunnes, W.: Summary of Theoretical and Practical Knowledge of Poor Adhesion Conditions Acquired since Publication of B 164/RP 2. Report DT 257 (B 164) published by the Office for Research and Experiments of the International Union of Railways (1992)

12. Gallardo-Hernandez, E.A., Lewis, R.: Twin disc assessment of wheel/rail adhesion. Wear 265, 1309-1316 (2008)

13. Mesures a Prendre Pour Ameliorer la Sensibilite au Shuntage des Circuits de Voie. UIC737-2 in French (1980)

14. Lewis, R., Dwyer-Joyce, R.S., Lewis, J.: Disc machine study of contact isolation during railway sanding. J. Rail Rapid Transit. 217, 11-24 (2003)

15. Lewis, R., Masing, J.: Static wheel/rail contact isolation due to track contamination. J. Rail Rapid Transit. 220, 43-53 (2006)

16. Fletcher, D.I., Beynon, J.H.: Development of a machine for closely controlled rolling contact fatigue and wear testing. J. Test. Eval. 28, 267-275 (2000)

17. European Standard EN13262: Railway Applications-Wheelsets and Bogies-Wheels-Product requirement. Standard CEN 13262 (2004)

18. Chen, H., Ban, T., Ishida, M., Nakahara, T.: Experimental investigation of influential factors on adhesion between wheel and rail under wet conditions. Wear 265, 1504-1511 (2008)

19. Lewis, R., Gallardo-Hernandez, E.A., Hilton, T., Armitage, T.: Effect of oil and water mixtures on adhesion in the wheel/rail contact. J. Rail Rapid Transit. 223, 275-283 (2009)

20. Lewis, R., Dwyer-Joyce, R.S.: Wear at the wheel-rail interface when sanding is used to increase adhesion. J. Rail Rapid Transit. 220, 29-41 (2006)

21. Arias-Cuevas, O., Li, Z., Lewis, R.: A laboratory investigation on the influence of the particle size and slip during sanding on the adhesion and wear in the wheel-rail contact. Paper to be presented at 8 th international conference on contact mechanics and wear of rail/wheel systems, Firenze, Italy, 15-18 September 2009

22. Astle-Fletcher, M.W.: Mechanical methods of improving rail adhesion. Proc. Inst. Mech. Eng. 178, 185-205 (1963-1964)

23. Arias-Cuevas, O., Li, Z., Lewis, R., Gallardo-Hernandez, E.A.: Laboratory investigation of some sanding parameters to improve the adhesion in leaf contaminated wheel-rail contacts. J. Rail Rapid Transit., in review (2009) 